\title{
Mapping and prediction of schistosomiasis in Nigeria using compiled survey data and Bayesian geospatial modelling
}

Uwem F. Ekpo ${ }^{1}$, Eveline Hürlimann ${ }^{2,3}$, Nadine Schur ${ }^{2,3}$, Akinola. S. Oluwole ${ }^{1}$, Eniola M. Abe ${ }^{1}$, Margaret A. Mafe ${ }^{4}$, Obiageli J. Nebe ${ }^{5}$, Sunday Isiyaku ${ }^{6}$, Francisca Olamiju ${ }^{7}$, Mukaila Kadiri ${ }^{1}$, Temitope O.S. Poopola ${ }^{8}$, Eka I. Braide ${ }^{9}$, Yisa Saka ${ }^{10}$, Chiedu F. Mafiana ${ }^{11}$, Thomas K. Kristensen $^{12,13}$, Jürg Utzinger ${ }^{2,3}$, Penelope Vounatsou ${ }^{2,3}$

${ }^{1}$ Spatial Parasitology and Health GIS Group, Department of Biological Sciences, Federal University of Agriculture, PMB 2240, 110001 Abeokuta, Nigeria; ${ }^{2}$ Department of Epidemiology and Public Health, Swiss Tropical and Public Health Institute, P.O. Box, CH-4002 Basel, Switzerland; ${ }^{3}$ University of Basel, P.O. Box, CH-4003 Basel, Switzerland; ${ }^{4}$ Department of Public Health, National Institute for Medical Research, Yaba, 101011 Lagos, Nigeria; ${ }^{5}$ Schistosomiasis/STH Control Programme, Department of Public Health, Federal Ministry of Health, Phase 3, 900211 Abuja, Nigeria; 'Sightsavers, Nigeria Country Office, 1 Golf Course Road, 800221 Kaduna, Nigeria; ${ }^{7}$ Mission to Save the Helpless (MITOSATH), 605 Hospital Place, Opposite Green Valley Suites, GRA, P.O. Box 205, 930001 Jos, Nigeria; ${ }^{8}$ Department of Microbiology, Federal University of Agriculture, PMB 2240, 110001 Abeokuta, Nigeria; ${ }^{9}$ Department of Animal and Environmental Biology, University of Calabar, 540242 Calabar, Nigeria; ${ }^{10}$ National Onchocerciasis Control Programme (NOCP), Department of Public Health, Federal Ministry of Health, Phase 3, 900211 Abuja, Nigeria; ${ }^{11}$ National Universities Commission, 26 Aguyi Ironsi Street, Maitama, 900271 Abuja, Nigeria; ${ }^{12}$ DBL, Department of Veterinary Disease Biology, University of Copenhagen, Thorvaldsensvej 57, DK-1871 Frederiksberg C, Denmark; ${ }^{13}$ School of Biological and Conservation Sciences, Faculty of Science and Agriculture, University of KwaZulu-Natal, Pietermaritzburg Campus, KawaZulu-Natal, South Africa

\begin{abstract}
Schistosomiasis prevalence data for Nigeria were extracted from peer-reviewed journals and reports, geo-referenced and collated in a nationwide geographical information system database for the generation of point prevalence maps. This exercise revealed that the disease is endemic in 35 of the country's 36 states, including the federal capital territory of Abuja, and found in 462 unique locations out of 833 different survey locations. Schistosoma haematobium, the predominant species in Nigeria, was found in 368 locations (79.8\%) covering 31 states, S. mansoni in $78(16.7 \%)$ locations in 22 states and S. intercalatum in $17(3.7 \%)$ locations in two states. S. haematobium and S. mansoni were found to be co-endemic in 22 states, while co-occurrence of all three species was only seen in one state (Rivers). The average prevalence for each species at each survey location varied between $0.5 \%$ and $100 \%$ for $S$. haematobium, $0.2 \%$ to $87 \%$ for $S$. mansoni and $1 \%$ to $10 \%$ for $S$. intercalatum. The estimated prevalence of $S$. haematobium, based on Bayesian geospatial predictive modelling with a set of bioclimatic variables, ranged from $0.2 \%$ to $75 \%$ with a mean prevalence of $23 \%$ for the country as a whole (95\% confidence interval (CI): $22.8-23.1 \%$ ). The model suggests that the mean temperature, annual precipitation and soil acidity significantly influence the spatial distribution. Prevalence estimates, adjusted for school-aged children in 2010 , showed that the prevalence is $<10 \%$ in most states with a few reaching as high as $50 \%$. It was estimated that 11.3 million children require praziquantel annually (95\% CI: 10.3-12.2 million).
\end{abstract}

Keywords: schistosomiasis, prevalence, geo-referencing, geographical information system, risk mapping, Bayesian geospatial modelling, control, Nigeria.

Corresponding author:

Uwem F. Ekpo

Spatial Parasitology and Health GIS Group

Department of Biological Sciences

Federal University of Agriculture

PMB 2240, 110001 Abeokuta, Nigeria

Tel. +234802755 5689

E-mail: ekpouf@unaab.edu.ng; ufekpo@hotmail.com
Introduction

More than 200 million people are thought to be infected with Schistosoma spp., with more than 95\% of all infections concentrated in Africa (Steinmann et al., 2006; Utzinger et al., 2009). Due to the requirement of an intermediate snail host, this trematode parasite thrives in areas characterised by poor sanitation and hygiene, poverty and general neglect, where rivers, 
lakes and irrigation schemes facilitate its continued transmission (WHO, 2002; Gryseels et al., 2006; Hotez and Kamath, 2009; Stothard et al., 2009; Utzinger et al., 2011).

Schistosomiasis has been classified as a neglected tropical disease (NTD), although an estimated 779 million people in the world are at risk for it according to relatively recent surveys (Steinmann et al., 2006; Hotez et al., 2007a). Three species (S. mansoni, $S$. haematobium and $S$. intercalatum) are endemic in Nigeria, which led to the formation of a national schistosomiasis control programme in the late 1980s. However, due to lack of political will and inadequate funding for control activities, the burden of schistosomiasis did not decline. Estimates in the mid-1990s suggested that more than 100 million people were at risk for this disease and that 25.8 million people were actually infected (Chitsulo et al., 2000). More recently, the latter figure was updated to 29 million infections (Steinmann et al., 2006; Moné et al., 2010), which corresponds to $14 \%$ of the global number of Schistosoma infections and puts Nigeria at the top of the list of endemic countries. To date, concerted efforts to control schistosomiasis in Nigeria have failed, not only due to the reasons given above, but also because reliable data regarding its geographical distribution are lacking. The paucity of empirical schistosomiasis estimates and endemic foci within states and local government areas (LGAs), the units usually used for health interventions, have proved a major impediment for the national control programme. Attempts to provide risk estimates at these units remain sporadic, but some information is available, e.g. from the state of Niger (Mafe et al., 2000) and more recently from the state of Ogun (Ekpo et al., 2008).

Several sub-Saharan African countries have received support from United Nations (UN) and nongovernmental organizations (NGOs) to control schistosomiasis along with other NTDs (Hotez et al., 2007 b). Nigeria, however, has only received limited international support due to absence of governmental commitment and reliable empirical data. Given the large population of the country and the high frequency of NTDs, including schistosomiasis, this situation will only change when the current neglect is translated into proactive action (Hotez et al., 2012). The ongoing global move to control and eventually eliminate the NTDs (IPPPH, 2009; BMGF, 2010; Utzinger, 2012; WHO, 2012; Rollinson et al., 2013) will likely result in many African nations receiving support to implement national control programmes.
Data compiled by the "Global Neglected Tropical Diseases" (GNTD) database (Hürlimann et al., 2011), supplemented with local geo-referenced survey data, will be helpful in this context. The work presented here was undertaken to help move the Nigerian schistosomiasis control programme forward by updating maps on the geographical distribution of the disease.

\section{Methods}

\section{Literature review}

A comprehensive literature review related to schistosomiasis survey data in Nigeria, using PubMed and other readily available bibliographic databases, was conducted under the umbrella of the EU-funded CONTRAST project (Kristensen, 2008). Details of how the GNTD database was established, including standard protocols for data extraction of relevant literature, have been presented elsewhere (Hürlimann et al., 2011). Additional specific searches were performed based on references from the retrieved publications. Websites of international organization, such as the World Health Organization (WHO) and the United Nations Children's Fund (UNICEF), were also consulted for schistosomiasis survey data and the Federal Ministry of Health, State Ministries of Health, NGOs, universities and local research institutions in Nigeria were contacted. Relevant data, including the number of those examined, age groups surveyed, Schistosoma species, sex ratio, diagnostic method, study approach and study location, were extracted and collated in a standardised database.

\section{Geo-referencing of identified survey data}

Data compiled in the GNTD database, supplemented with recent surveys and reports obtained from the aforementioned sources were analysed. For a detailed description of the various data sources, the data extraction process, the database system and internal quality checks, the reader is invited to consult recently published papers, e.g. Hürlimann et al. (2011) Schur et al. (2013) and Stensgaard et al. (2013). Studies lacking information about the geographical coordinates of survey locations were retrospectively geo-referenced using a variety of sources, such as GEOnet Names Servers (http://earthinfo.nga.mil/gns/html/index.html) and Google maps (http://maps.google.com). If this was not possible, the reported locations were visited for geo-referencing 
using a hand-held global positioning system (GPS) receiver (Garmin Etrex, Garmin Corporation, USA). The analyses presented here are restricted to school children of the 5 to 14 years age group and non-hospital records.

\section{Population data}

Population data at the $1 \mathrm{~km}^{2}$ spatial resolution in Nigeria for 2010 were obtained from the AfriPop population database (http://www.clas.ufl.edu/users/atatem/ index_files/Nigeria.htm). The total population count for 2010 was $150,511,635$ persons. The number of school-aged children in Nigeria in 2010 was computed to be $40,337,118$, which represents $26.8 \%$ of the total population count based on information in the international database of the United States Census Bureau (http://www.census.gov/population/ international/data/idb/region.php).

Mapping and Bayesian geospatial modelling of S. haematobium presence

Climatic and environmental data, going back to the 1950s, were obtained from the WorldClim-Global Climatic Data source (http://worldclim.org/bioclim); the Earth Resources Observation (EROS) centre (http://eros.usgs.gov), and the International Soil Reference and Information Centre (ISRIC) (http://www.isric.org).

With regard to geospatial modelling, we first carried out bivariate logistic regressions to determine the relationship between the risk of $S$. haematobium infection and the potential climatic and environmental variables. Next, Bayesian geostatistical logistic regression models with location-specfic random effects were fitted to identify the most significant predictors using advanced variable selection procedures (Schur et al., 2013). Bayesian geostatistical models, fitted by Markov chain Monte Carlo (MCMC) simulation methods (Diggle et al., 1998) were employed to estimate infection risk of $S$. haematobium at unobserved locations via joint Bayesian kriging. A grid of prediction locations with a spatial resolution of $5 \times 5 \mathrm{~km}$ was used, resulting in 30,051 pixels.

\section{School-aged population infected with Schistosoma}

The total population data grid map with $1 \times 1 \mathrm{~km}$ spatial resolution was rescaled to a $5 \times 5 \mathrm{~km}$ resolution grid using the geographical information system (GIS) software ArcMap version 9.2 (ESRI, Redlands,
CA, USA) to match the spatial resolution of the geostatistical S. haematobium risk estimates for Nigeria. Population counts were linked to the percentage of school-aged children within each predicted pixel level. The estimated number of infected school-aged children with $S$. haematobium infection was calculated by combining the median predictive posterior distribution of the infection prevalence predicted at the pixel level with the population size of that age group within that pixel. The median predictive posterior distribution of the number of infected school-aged children per state was estimated by summing up the pixel-samples within each state and calculating summary statistics. The calculation was carried out as follows: assuming that the pixel value of the population data grid at location $x=a$, then the estimated school-aged population $y$ at location $x$ is 26.8 (the percentage share of the population accepted to consist of children) divided by 100 multiplied by $a$. Therefore the number of infected school-aged population is the summed values of $y_{1}, y_{2}, \ldots, y_{n}$, where the predicted $S$. haematobium pixel value is greater than zero.

\section{Data aggregation by state and praziquantel treatment requirement}

The national schistosomiasis control programme in Nigeria is implemented by the State Ministries of Health and NGOs under the supervision of the Federal Ministry of Health. Shape files containing geographical information by state administrative boundaries were linked in ArcMap with S. haematobium risk estimates and school-aged populations to estimate the number of infected children at the pixel-level. Population-adjusted prevalence estimates at the state level were calculated by summing all infected schoolaged children at the pixel-level and dividing by the total school-aged population by state.

Praziquantel, the drug used for treatment of schistosomiasis, is usually administered as a single oral dose of $40 \mathrm{mg} / \mathrm{kg}$ (WHO, 2006; Doenhoff et al., 2008). The drug requirements were computed using the estimated number of infected school-aged children and multiplying by the estimated number of praziquantel tablets needed per child. Based on guidelines put forth by WHO (2006), the average school-aged child requires three tablets used as a single treatment every year in moderate endemicity settings (prevalence of $10-50 \%$ ). The treatment needs were calculated for each state for the year 2010 following the same approach as recently presented by Schur et al. (2012). 


\section{Results}

Temporal analysis of schistosomiasis survey data in Nigeria

An overview of the points in time when schistosomiasis surveys were conducted in Nigeria is given in Fig. 1. The first surveys pertaining to schistosomiasis were carried out in Nigeria before its independence in 1960. Later on, particularly between 1986 and 1990, a considerable number of surveys were done as the government had a growing interest in disease control at that time. This resulted in the establishment of the first national schistosomiasis control programme in 1988 (Federal Ministry of Health, 1997). However, the failure of the control programme to implement large-scale control activities led to a decrease of surveys between 1992 and 2003. The spike in reported surveys in 2004 may be due to particular activities that year by different NGOs, most importantly the Carter Center (http://www.cartercenter.org/index.html) (Eigege et al., 2008; Njepuome et al., 2009). Since 2006, the number of surveys has increased steadily as the prospect of new initiatives to control schistosomiasis as part of packages targeting additional, multiple NTDs (e.g. onchocerciasis, lymphatic filariasis and soil-transmitted helminthiasis) became reality.

Geographical distribution of schistosomiasis in Nigeria

Schistosomiasis is endemic in all but one of the 36 states of Nigeria. The Akwa Ibom State in the south- ern part of the country is the only state where, to date, no endemic foci of either S. haematobium or S. mansoni has been reported. Our empirical data reveal that S. haematobium is the predominant species in the country, accounting for $79.8 \%$ of all reported cases, while the rate of $S$. mansoni reached $16.7 \%$ and that of $S$. intercalatum $3.7 \%$. Fig. 2 shows the map of Nigeria depicting its states and Abuja. Fig. 3 shows the distribution of all georeferenced survey locations in Nigeria with Schistosoma infections. S. haematobium and $S$. mansoni are both endemic in northern and southern Nigeria, while $S$. intercalatum has only been reported from the states of Bayelsa and Rivers in the Niger delta. In the 22 states where $S$. mansoni exists, $S$. haematobium is co-endemic, but co-distribution of all three Schistosoma species (i.e. S. haematobium, $S$. mansoni and S. intercalatum) has only been reported from the state of Rivers.

$S$. haematobium is the most prevalent of the three species among school-aged children and it often exceeds the high-endemicity threshold of $50 \%$ prevalence. Although this infection is comparatively more frequent in the South, it is also widespred in the rest of the country in contrast to $S$. mansoni infections, which are clearly more common in the northern half of the country. There are also differences with respect to intensity of disease as can be seen in Figs. 4-6, which show the geographical distribution of the three schistosome species in Nigeria, according to the WHO (2002) classification of schistosomiasis rates of prevalence (i.e. $0.1-9.9 \%$, low prevalence; 10.0 $49.9 \%$, moderate prevalence; and $\geq 50 \%$, high prevalence).

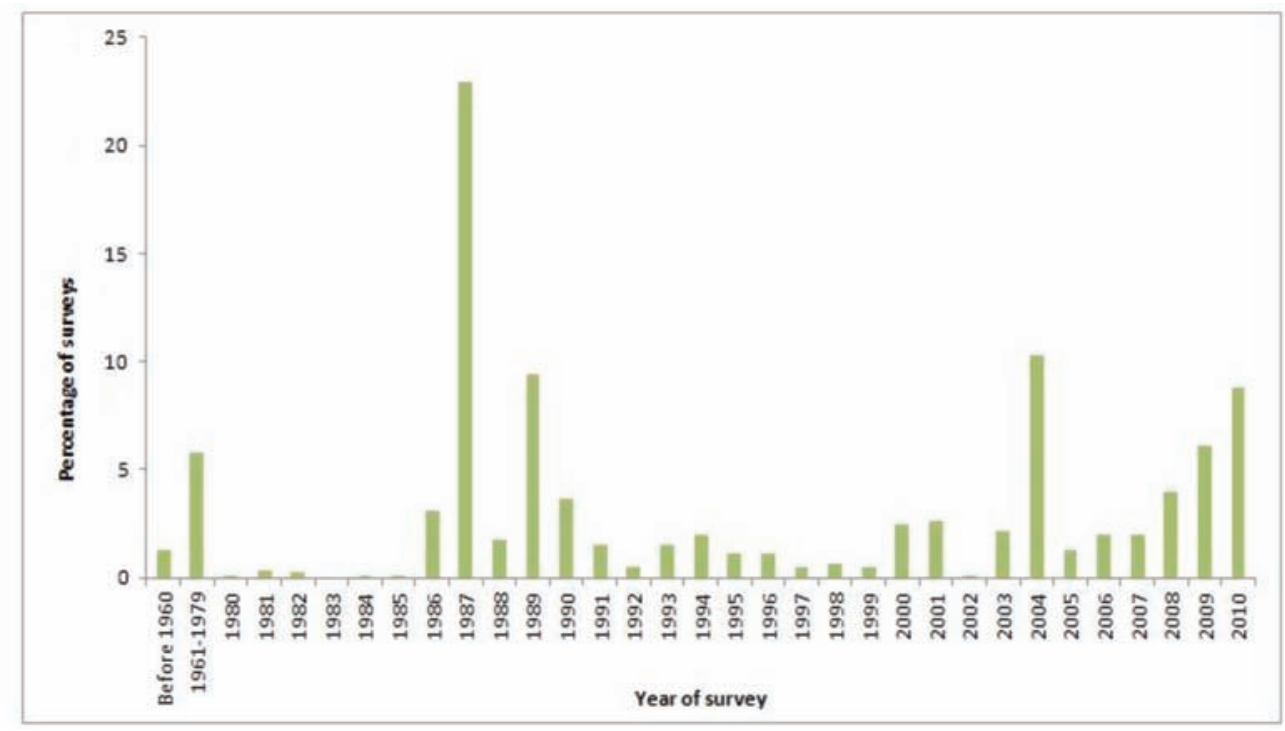

Fig. 1. Time-period of included georeferenced schistosomiasis prevalence surveys in Nigeria. 


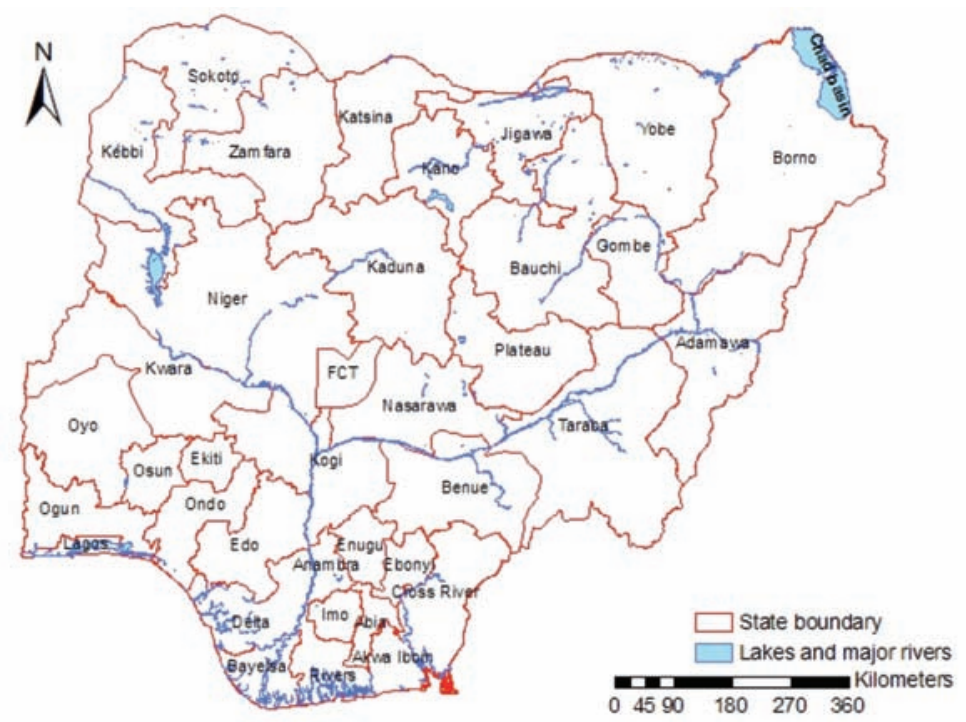

Fig. 2. Map of Nigeria showing the 36 states and the federal capital territory (FCT) of Abuja.

\section{S. haematobium risk maps}

The geostatistical model for S. haematobium suggests that the annual mean temperature, annual precipitation, precipitation seasonality and soil acidity are associated with S. haematobium risk in Nigeria. The parameter estimates included in Table 1 indicate that these variables were significant covariates in the final model, as their values from $25 \%$ SD to $75 \%$ SD includes zero.

The spatial distribution of $S$. haematobium risk throughout the country is shown in Fig. 7. Areas of high infection risk $(>50 \%)$ were predicted for locations around the Niger and Benue rivers, as well as locations near the Lake Chad basin. Moreover, high risk areas were identified in the south-western and north-western parts of Nigeria. The map of the prediction error for $S$. haematobium shows that areas of relatively high uncertainty $(75 \%$ quintile) are concentrated in areas of high infection risk, whereas areas of low uncertainty (25\% quintile) are mainly found in low-risk areas. Aggregated prevalence levels for each state are shown in Fig. 8A. States with a moderate infection risk are Sokoto, Kebbi, Kwara, Niger, Zamfara and Kogi. Additionally, states along Benue River (Benue, Taraba, Nasarawa, FCT and Adamawa) and in the Lake Chad basin area (Bornu and Yobe) showed moderate infection prevalence. Other inland areas of moderate risk for S. haematobium include the



Fig. 3. Geographical distribution of reported schistosomiasis cases in Nigeria, stratified by the three existing Schistosoma species. 


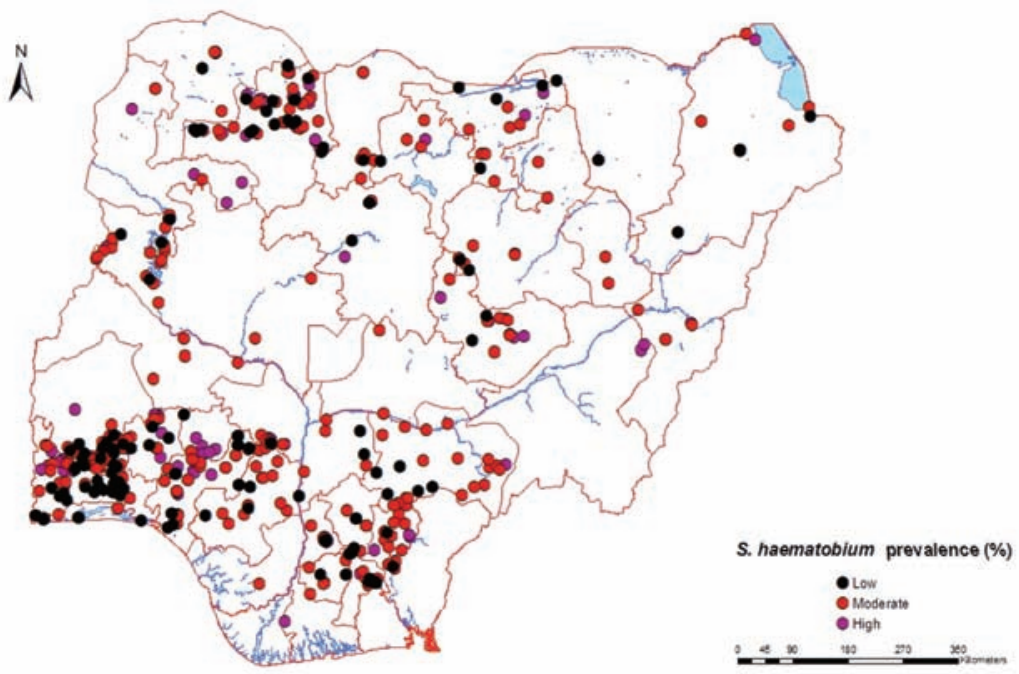

Fig. 4. Observed prevalence of S. haematobium in Nigeria including 368 georeferenced survey locations.

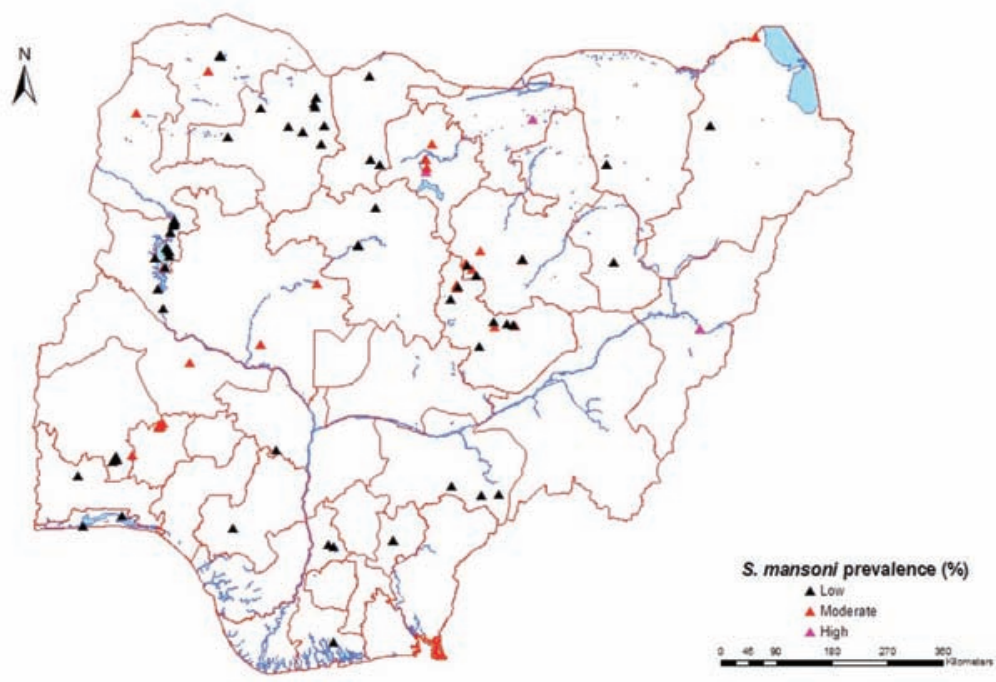

Fig. 5. Observed prevalence of S. mansoni in Nigeria including 78 georeferenced survey locations.

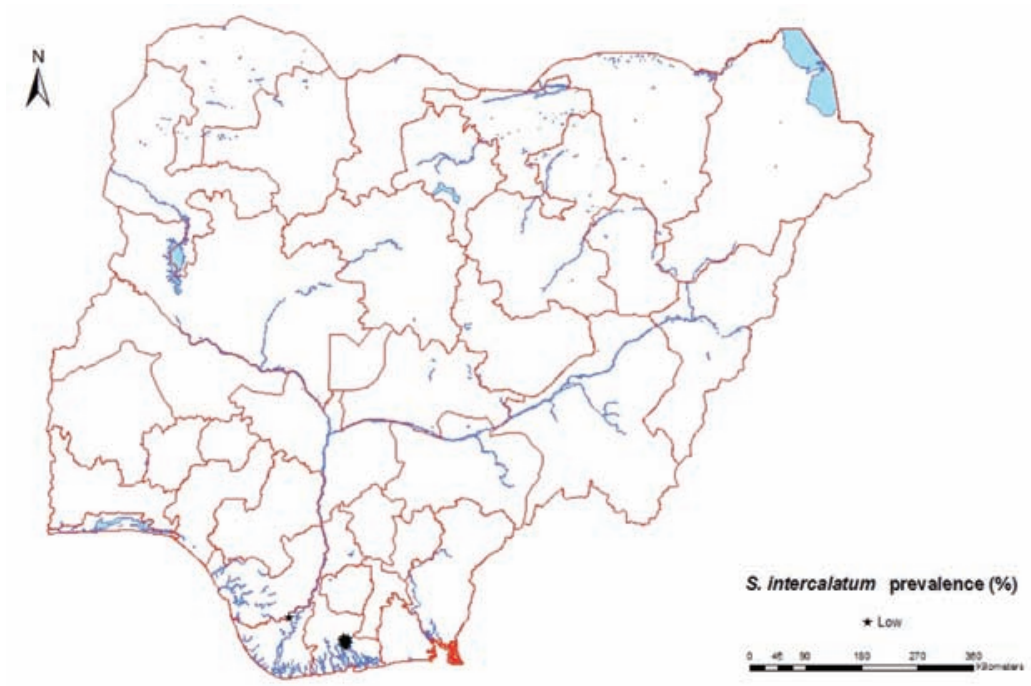

Fig. 6. Observed prevalence of S. intercalatum in Nigeria including 17 georeferenced survey locations. 
Table 1. Model parameter estimates for S. haematobium in Nigeria using Bayesian regression.

\begin{tabular}{lccccc}
\hline Variable & Mean & SD & $25 \%$ SD & Median & $75 \%$ SD \\
\hline Annual mean temperature & 0.459 & 0.336 & 0.148 & 0.382 & 1.675 \\
Annual precipitation & -1.071 & 0.420 & -1.641 & -1.129 & 0.064 \\
Precipitation seasonality & -0.596 & 0.589 & -1.100 & -0.715 & 1.698 \\
Soil acidity & 0.533 & 0.297 & -0.341 & 0.581 & 0.951 \\
\hline
\end{tabular}

SD, standard deviation

states Ogun, Oyo and Osun in the south-western part of the country. Areas of low risk $(<10 \%)$ were found in the southern part of Nigeria (i.e. the states of Delta, Edo, Enugu, Anambra and Ebonyi) and in the northern part (i.e. Plateau, Gombe, Bauchi, Kaduna and Katsina). There are, however, also low-risk states in the Niger delta, e.g. Rivers, Imo, Abia, Akwa Ibom, Bayelsa and the southern parts of Cross River. The map reveals that most of the states in Nigeria are characterised by either low or moderate risk with no state considered to be at high risk. Still, high-risk communities with prevalence in excess of $50 \%$ were found in several states (Fig. 8B).

\section{School-aged population infected and treatment} requirements

State-specific estimates of the number of schoolaged children infected with Schistosoma, and hence requiring praziquantel treatment as of 2010 are shown in Table 2. The results suggest that the total number of infected school-aged children in Nigeria is 11.3 million (95\% confidence interval (CI): 10.3-12.2 million). The state of Anamabra in southern Nigeria was found to have the highest number of infected school-aged children, while the Enugu state in the
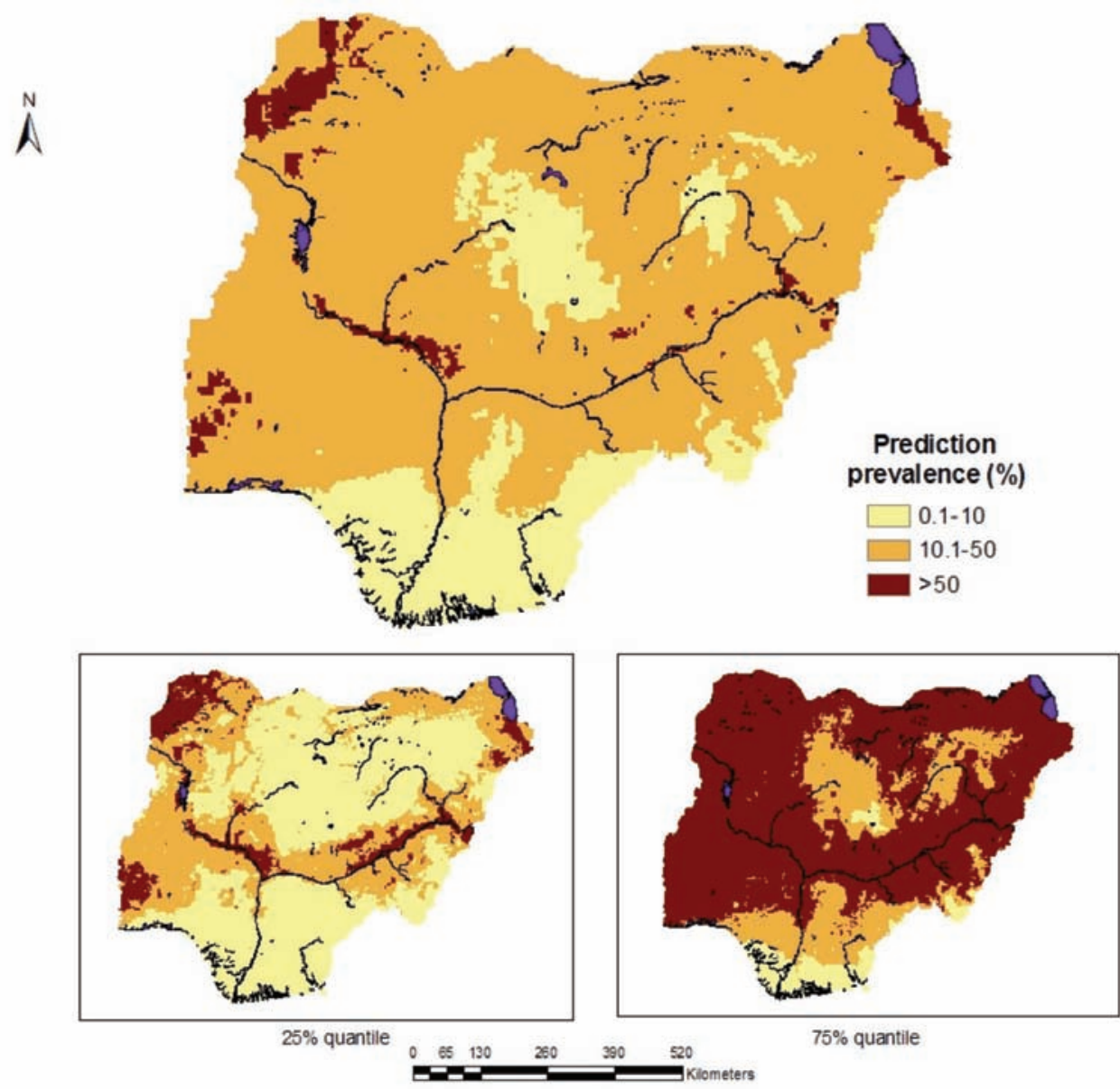

Fig. 7. The predicted median posterior distribution of infection risk of S. haematobium in Nigeria based on Bayesian geostatistics and predicted error maps. 

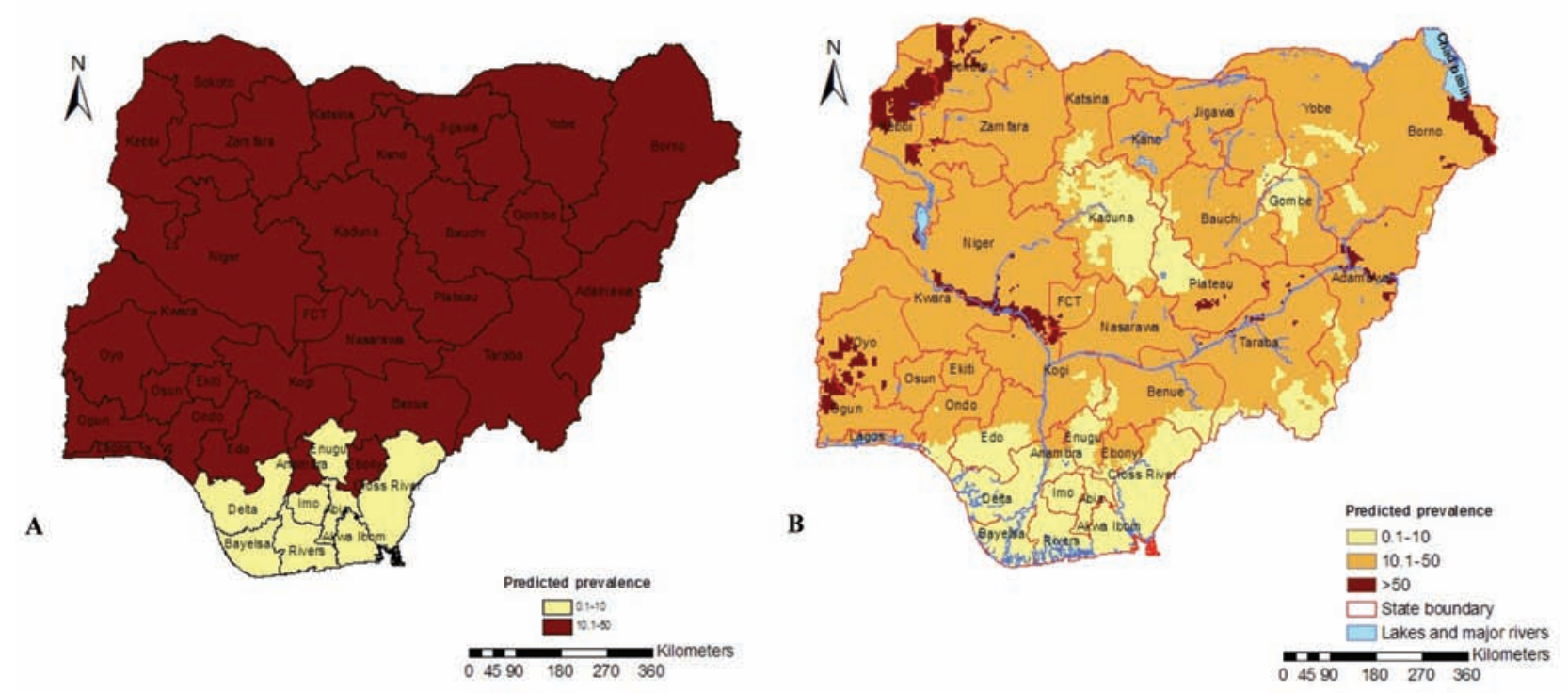

Fig. 8. Prevalence estimates of $S$. haematobium for the 36 states in Nigeria including the federal capital territory (FCT) of Abuja. Prevalences (based on the 2002 WHO classification) are shown at the state level (A) and the pixel level (B).

same region had the lowest. The number of praziquantel tablets required for treating the predicted number of school-aged children was estimated at 34 million tablets for 2010 .

\section{Discussion}

The paucity of detailed information on schistosomiasis distribution in Nigeria hampers the implementation of the national control programme. Risk maps were produced to facilitate the targeting of schistosomiasis control activities, planning of future surveys and surveillance. The first detailed hard-copy maps of the global distribution of schistosomiasis were published a quarter century ago (Doumenge et al., 1987). With the advent of desktop GIS and mapping software, the application of GIS for creating digital disease maps became feasible and these proved extremely useful for the planning, control and surveillance of human helminth infections (Brooker and Michael, 2000; Brooker et al., 2000, 2009, 2010; Simoonga et al., 2009). However, with the exception of a single state, Ogun (Ekpo et al., 2008) and despite several surveys pertaining to the distribution of schistosomiasis and the intermediate host snails in Nigeria, the first ones dating back to the 1930s (Ramsay, 1934; Cowper 1963, 1973; WHO, 1985), the compilation of these records into a comprehensive GIS-based overview did not exist before the current study.
In 2010, a project known as the "Global Atlas of Helminth Infections" (GAHI; http://www.thiswormyworld.org) started to offer digital maps on the spatial distribution of helminth infection in subSaharan Africa, including Nigeria. However, only maps of the observed prevalence at compiled survey locations are available (Brooker et al., 2010) and the underlying survey data are not provided for in-depth analyses. In 2011, the open-access GNTD database containing georeferenced schistosomiasis prevalence data was launched to fill this gap. This database allows extraction of compiled prevalence data from various published and unpublished sources for many different countries (Hürlimann et al., 2011), which stimulated spatially explicit analyses, such as risk mapping, studies of the distribution of intermediate host snails and estimates of treatment needs for the school-aged population (Schur et al., 2011, 2012, 2013; Stensgaard et al., 2013). Employing this rich source of schistosomiasis survey data, the geographical distributions of the three human Schistosoma species that occur in Nigeria have been mapped. High-risk areas have been identified allowing prioritization of areas warranting control interventions. The data also permit temporal analyses, which should assist the planning of future surveys. The current priority would be to focus on areas where data are particularly sparse so that cost-effectiveness of mapping and subsequent control interventions can be enhanced. 
Table 2. The numbers of school-aged children infected with S. haematobium and the praziquantel (PZQ) treatment requirements in 2010 shown by state.

\begin{tabular}{|c|c|c|c|c|c|c|c|}
\hline $\mathrm{S} / \mathrm{N}$ & State & Population & $\begin{array}{c}\begin{array}{c}\text { School-aged } \\
\text { children }^{a}\end{array} \\
\end{array}$ & $\begin{array}{c}\text { Numbers } \\
\text { infected }\end{array}$ & $95 \% \mathrm{CI}$ & Prevalence $^{\mathrm{b}}$ & $\begin{array}{c}\text { PZQ tablets } \\
\text { required }\end{array}$ \\
\hline 1 & Abia & $3,088,489$ & 827,715 & 217,860 & $93,415-342,301$ & 28.9 & 653,580 \\
\hline 2 & Adamawa & $3,345,139$ & 896,497 & 264,130 & $194,336-333,924$ & 27.9 & 792,390 \\
\hline 3 & Akwa Ibom & $4,079,860$ & $1,093,403$ & 268,540 & 143-088-393,992 & 24.9 & 805,620 \\
\hline 4 & Anambra & $4,554,555$ & $1,220,621$ & 419,070 & $268,378-569,762$ & 37.5 & $1,257,210$ \\
\hline 5 & Bauchi & $4,904,861$ & $1,314,503$ & 377,820 & $195,112-560,528$ & 26.4 & $1,133,460$ \\
\hline 6 & Bayelsa & $1,764,882$ & 472,989 & 140,330 & $793,312-201,387$ & 29.3 & 420,990 \\
\hline 7 & Benue & $4,489,165$ & $1,203,096$ & 327,020 & $234,170-419,870$ & 25.2 & 981,060 \\
\hline 8 & Bornu & $4,458,940$ & $1,194,996$ & 320,720 & $214,734-426,706$ & 25.6 & 962,160 \\
\hline 9 & Cross River & $3,059,240$ & 819,876 & 181,730 & $124,771-238,689$ & 22.5 & 545,190 \\
\hline 10 & Delta & $4,367,659$ & $1,170,533$ & 408,840 & $256,895-560,785$ & 36.5 & $1,226,520$ \\
\hline 11 & Ebonyi & $2,301,621$ & 616,834 & 113,330 & $84,650-142,009$ & 17.8 & 339,990 \\
\hline 12 & Edo & $3,498,159$ & 937,507 & 245,390 & $158,146-332,634$ & 28.8 & 736,170 \\
\hline 13 & Ekiti & $2,580,707$ & 691,630 & 252,000 & $110,248-393,752$ & 37.3 & 756,000 \\
\hline 14 & Enugu & $3,461,328$ & 927,636 & 132,180 & $83,934-180,426$ & 15.4 & 396,540 \\
\hline 15 & Abuja* & $1,490,699$ & 399,507 & 114,410 & $62,293-166,527$ & 32.9 & 343,230 \\
\hline 16 & Gombe & $2,504,758$ & 671,275 & 157,520 & $103,704-211,336$ & 21.5 & 472,560 \\
\hline 17 & Imo & $4,125,237$ & $1,105,563$ & 362,510 & $197,502-527,519$ & 34.5 & $1,087,530$ \\
\hline 18 & Jigawa & $4,638,479$ & $1,243,112$ & 397,130 & $192,366-601,894$ & 30.4 & $1,191,390$ \\
\hline 19 & Kaduna & $6,529,746$ & $1,749,972$ & 405,680 & $319,280-492,080$ & 22.3 & $1,217,040$ \\
\hline 20 & Kano & $10,215,494$ & $2,737,752$ & 979,360 & $588,134-137,059$ & 34.1 & $2,938,080$ \\
\hline 21 & Katsina & $6,186,868$ & $1,658,081$ & 607,710 & $382,804-832,616$ & 34.3 & $1,823,130$ \\
\hline 22 & Kebbi & $3,442,422$ & 922,569 & 287,040 & $199,605-374,475$ & 28.3 & 861,120 \\
\hline 23 & Kogi & $3,521,364$ & 943,726 & 307,490 & $145,307-469,673$ & 31.6 & 922,470 \\
\hline 24 & Kwara & $2,558,692$ & 685,729 & 250,590 & $140,882-360,298$ & 36.7 & 751,770 \\
\hline 25 & Lagos & $10,518,608$ & $2,818,987$ & 605,610 & $196,764-1,014,456$ & 30.5 & $1,816,830$ \\
\hline 26 & Nasarawa & $1,966,300$ & 526,968 & 135,250 & $108,667-161,833$ & 24.6 & 405,750 \\
\hline 27 & Niger & $4,187,613$ & $1,122,280$ & 304,400 & $237,572-371,228$ & 25.7 & 913,200 \\
\hline 28 & Ogun & $4,120,568$ & $1,104,312$ & 256,540 & $161,192-351,886$ & 26.0 & 769,620 \\
\hline 29 & Ondo & $3,708,369$ & 993,843 & 265,080 & $162,334-367,826$ & 27.4 & 795,240 \\
\hline 30 & Osun & $3,761,319$ & $1,008,034$ & 317,570 & $157,996-476,004$ & 33.7 & 952,710 \\
\hline 31 & Oyo & $6,139,127$ & $1,645,286$ & 375,570 & $253,224-497,916$ & 24.6 & $1,126,710$ \\
\hline 32 & Plateau & $3,400,482$ & 911,329 & 214,350 & $180,740-247,960$ & 22.6 & 643,050 \\
\hline 33 & Rivers & $5,316,003$ & $1,424,689$ & 409,620 & $117,376-701,864$ & 29.6 & $1,228,860$ \\
\hline 34 & Sokoto & $3,954,209$ & $1,059,728$ & 282,900 & $168,807-396,993$ & 25.4 & 848,700 \\
\hline 35 & Taraba & $2,385,772$ & 639,387 & 182,660 & $137,065-228,255$ & 26.7 & 547,980 \\
\hline 36 & Yobe & $2,475,468$ & 663,425 & 143,130 & $95,624-190,636$ & 20.1 & 429,390 \\
\hline \multirow[t]{2}{*}{37} & Zamfara & $3,409,431$ & 913,728 & 238,660 & $152,239-325,081$ & 23.8 & 715,980 \\
\hline & Total & $150,511,635$ & $40,337,118$ & $11,270,720$ & $10,339,510-12,198,830$ & 27.9 & $33,812,160$ \\
\hline
\end{tabular}

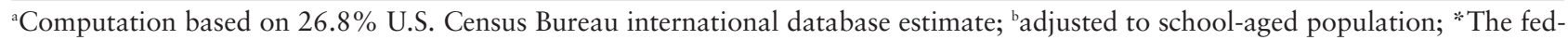
eral capital territory of Abuja is considered equivalent of a state

The data used in the current analyses were extracted from peer-reviewed publications and a variety of reports, and hence differ with regard to survey dates, the diagnostic method used and the populations surveyed. To minimise bias, we restricted our analysis to surveys focussing on school-aged children (5-14 years), who constitute the target group for preventive chemotherapy in schistosomiasis control programmes (WHO, 2002, 2006). We present the first smooth empirical risk map for $S$. haematobium across Nigeria at a spatial resolution of $5 \times 5 \mathrm{~km}$. Previous mapping efforts using remotely sensed climatic variables have been based on data from the Moderate-Resolution Imaging Spectroradiometer (MODIS) satellites data 
archives (http://wist.echo.nasa.gov) (Schur et al., 2011, 2013). We used readily available BioClim data dating back to the 1950s and employed advanced variable selection methods.

In the current analysis, we estimated the number of school-aged children infected with $S$. haematobium to be 11.3 million, which corresponds to 34 million praziquantel tablets for their treatment. The estimates might be slightly higher if the other two Schistosoma species (i.e. S. mansoni and S. intercalatum) were considered as well (Schur et al., 2012). Giving the average annual population growth rate for Nigeria to be $2.5 \%$, the required number of praziquantel tablets might increase every year by a percentage close to that ot the growth rate. As several international donors have shown interest in supplying the drug for free, only the cost for distribution and other logistic requirements need to be considered to calculate the cost-effectiveness of this preventive chemotherapy strategy. Nevertheless, the provision of data such as presented here will enable the national control programme to leverage evidence-based information for sourcing of funds. As more geostatistical model-based analysis from the GNTD database will become available for Nigeria and elsewhere, it is our hope that control of schistosomiasis in Nigeria and indeed Africa will be accelerated, as reliable risk estimates at high spatial resolution will reduce the cost of parasitological surveys.

Schistosomiasis is a focal disease depending entirely on freshwater systems harbouring the intermediate host snails. Moreover, human activities (e.g. bathing, washing and fishing) promote contacts with infested water, since excreted parasite eggs must reach freshwater sources, hatch and penetrate a suitable snail intermediate host (Lengeler et al., 2002; Brooker et al., 2009; Utzinger et al., 2011). Therefore, any reduction in the prevalence of infection in areas without chemotherapeutic intervention can only be due to improvement in any or all of the following: water supply and sanitation and/or health education and awareness and avoidance of transmission sites. It is noteworthy that these preventive control measures are still often neglected in Nigeria. Indeed, effective control measures have been demonstrated in very limited areas such as in Plateau and Nasarawa states in northcentral Nigeria (Hopkins et al., 2002; Njepuome et al., 2009). Thus the endemic foci documented in this analysis are still relevant for control. Therefore, stakeholders interested in schistosomiasis control might find the data, provided maps and endemic foci useful for their operational purposes.

\section{Conclusion}

Based on data compiled from the GNTD database supplemented with local data for the creation of point prevalence maps, we performed model-based Bayesian geostatistical estimation of schistosomiasis infection prevalence for unobserved locations and computed the number of infected school-aged children and praziquantel treatment requirement for Nigeria. This should accelerate control activities and help attract resources to implement a sustainable control programme capable of reducing the burden of schistosomiasis in Nigeria.

\section{Acknowledgements}

We thank all authors, organizations and individuals who contributed published and unpublished data used in the generation of these maps and endemic foci. The work was carried out by U.F. Ekpo under a junior postdoctoral fellowship programme of the European Foundation Initiative for African Research into Neglected Tropical Diseases (EFINTD; project grant no: AZ:I/84003, entitled "Development of a nationwide geographical information system database and Bayesian spatial predictive models for the control of schistosomiasis in Nigeria"). The funding enabled U.F. Ekpo to collaborate on the Nigerian dataset within the EU-funded CONTRAST project.

\section{References}

BMGF, 2010. Our Work in Neglected Diseases: Visceral Leishmaniasis, Guinea Worm, Rabies - Overview and Approach. Seattle: Bill and Melinda Gates Foundation [Internet] 2010 (available at: http://www.gatesfoundation.org /topics/Pages/neglected-diseases.aspx; accessed: 10 August 2011).

Brooker S, Hotez PJ, Bundy DAP, 2010. The global atlas of helminth infection: mapping the way forward in neglected tropical disease control. PLoS Negl Trop Dis 4, e779.

Brooker S, Kabatereine NB, Gyapong JO, Stothard JR, Utzinger J, 2009. Rapid mapping of schistosomiasis and other neglected tropical diseases in the context of integrated control programmes in Africa. Parasitology 136, 1707-1718.

Brooker S, Michael E, 2000. The potential of geographical information systems and remote sensing in the epidemiology and control of human helminths infections. Adv Parasitol 47, 246-288.

Brooker S, Rowlands M, Haller L, Savioli L, Bundy DAP, 2000. Towards an atlas of human helminth infection in sub-Saharan Africa: the use of geographical information systems (GIS). Parasitol Today 16, 303-307.

Chitsulo L, Engels D, Montresor A, Savioli L, 2000. The global 
status of schistosomiasis and its control. Acta Trop 77, 41-51. Cowper SG, 1963. Schistosomiasis in Nigeria. Ann Trop Med Parasitol 57, 307-322.

Cowper SG, 1973. Bilharziasis (schistosomiasis) in Nigeria. Trop Geogr Med 25, 105-118.

Diggle, PJ, Tawn JA, Moyeed RA, 1998. Model-based geostatistics. Appl Stat 47, 299-350.

Doenhoff MJ, Cioli D, Utzinger J, 2008. Praziquantel: mechanisms of action, resistance and new derivatives for schistosomiasis. Curr Opin Infect Dis 21, 659-667.

Doumenge JP, Mott KE, Cheung C, Villenave D, Chapuis O, Perrin MF, Reaud-Thomas G, 1987. Atlas of the global distribution of schistosomiasis. Presses Universitaires de Bordeaux.

Eigege A, Pede E, Miri E, Umaru J, Ogbu Pearce P, Jinadu MY, Njepuome AN, 2008. Triple drug administration (TDA) with praziquantel, ivermectin and albendazole, for the prevention of three neglected tropical diseases in Nigeria. Ann Trop Med Parasitol 102, 1-3.

Ekpo UF, Mafiana CF, Adeofun CO, Solarin ART, Idowu AB, 2008. Geographical Information systems and predictive risk maps of urinary schistosomiasis in Ogun State, Nigeria. BMC Infect Dis 8, 74.

Federal Ministry of Health, 1997. National Plan of Action in Schistosomiasis Control in Nigeria, 1997-2001. Abuja, Nigeria: Federal Ministry of Health.

Gryseels B, Polman K, Clerinx J, Kestens L, 2006. Human schistosomiasis. Lancet 368, 1106-1118.

Hopkins DR, Eigege A, Miri ES, Gontor I, Ogah G, Umaru J, Gwomkudu CC, Mathai WA, Jinadu MY, Amadiegwu S, Oyenekan OK, Korve K, Richards FO Jr., 2002. Lymphatic filariasis elimination and schistosomiasis control in combination with onchocerciasis control in Nigeria. Am J Trop Med Hyg 67, 266-272.

Hotez P, Raff S, Fenwick A, Richards F. Jr, Molyneux DH, 2007b. Recent progress in integrated neglected tropical disease control. Trends Parasitol 23, 511-514.

Hotez PJ, Asojo OA, Adesina AM, 2012. Nigeria: “Ground Zero" for the high prevalence neglected tropical diseases. PLoS Negl Trop Dis 6, e1600.

Hotez PJ, Kamath A, 2009. Neglected tropical diseases in subSaharan Africa: review of their prevalence, distribution, and disease burden. PLoS Negl Trop Dis 3, e412.

Hotez PJ, Molyneux DH, Fenwick A, Kumaresan J, Ehrlich Sachs S, Sachs JD, Savioli L, 2007a. Control of neglected tropical diseases. N Engl J Med 357, 1018-1027.

Hürlimann E, Schur N, Boutsika K, Stensgaard AS, de Himpsl ML, Ziegelbauer K, Laizer N, Camenzind L, Di Pasquale A, Ekpo UF, Simoonga C, Mushinge G, Saarnak CFL, Utzinger J, Kristensen TK, Vounatsou P, 2011. Toward an open-access global database for mapping, control, and surveillance of neglected tropical diseases. PLoS Negl Trop Dis 5, e1404.

IPPPH 2009. Available at: http://www.globalforumhealth.org/
About/Research-initiatives/IPPPH (accessed: 10 August 2011). Kristensen TK, 2008 African schistosomiasis: refocusing upon the environment. Newsl R Soc Trop Med Hyg 13, 1-8.

Lengeler C, Utzinger J, Tanner M, 2002. Questionnaires for rapid screening of schistosomiasis in sub-Saharan Africa. Bull World Health Organ 80, 235-242.

Mafe MA, von Stamm T, Utzinger J, N'Goran EK, 2000. Control of urinary schistosomiasis: an investigation into the effective use of questionnaires to identify high-risk communities and individuals in Niger State, Nigeria. Trop Med Int Health 5, 53-63.

Moné H, Ibikounlé M, Massougbodji A, Mouahid G, 2010. Human schistosomiasis in the economic community of West African states: epidemiology and control. Adv Parasitol 71, 33-91.

Njepuome NA, Hopkins DR, Richards FO Jr, Anagbogu IN, Pearce PO, Jibril MM, Okoronkwo C, Sofola OT, Withers PC Jr., Ruiz-Tiben E, Miri ES, Eigege A, Emukah EC, Nwobi BC Jiya JY, 2009. Nigeria's war on terror: fighting dracunculiasis, onchocerciasis, lymphatic filariasis, and schistosomiasis at the grassroots. Am J Trop Med Hyg 80, 691-698.

Ramsay GW, 1934. A study on schistosomiasis and certain other helminthic infections in northern Nigeria. West Afr Med J 8, 2-10.

Rollinson D, Knopp S, Levitz S, Stothard JR, Tchuenté LA, Garba A, Mohammed KA, Schur N, Person B, Colley DG, Utzinger J, 2013. Time to set the agenda for schistosomiasis elimination. Acta Trop (in press; http://dx.doi.org/10.1016/ j.actatropica.2012.04.013).

Schur N, Hürlimann E, Garba A, Traore MS, Ndir O, Ratard RC, Tchuem Tchuenté LA, Kristensen TK, Utzinger J, Vounatsou P, 2011. Geostatistical model-based estimates of schistosomiasis prevalence among individuals aged $\leq 20$ years in West Africa. PLoS Negl Trop Dis 5, e1194.

Schur N, Hürlimann E, Stensgaard AS, Chimfwembe K, Mushinge G, Simoonga C, Kabatereine NB, Kristensen TK, Utzinger J, Vounatsou P, 2013. Spatially explicit Schistosoma infection risk in eastern Africa using Bayesian geostatistical modelling. Acta Trop (in press; http://dx.doi.org/10.1016/ i.atcatropica.2011.10.006).

Schur N, Vounatsou P, Utzinger J, 2012. Determining treatment needs at different spatial scales using geostatistical modelbased risk estimates of schistosomiasis. PLoS Negl Trop Dis 6, e1773.

Simoonga C, Utzinger J, Brooker S, Vounatsou P, Appleton CC, Stensgaard AS, Olsen A, Kristensen TK, 2009. Remote sensing, geographical information system and spatial analysis for schistosomiasis epidemiology and ecology in Africa. Parasitology 136, 1683-1693.

Steinmann P, Keiser J, Bos R, Tanner M, Utzinger J, 2006. Schistosomiasis and water resources development: systematic review, meta-analysis, and estimates of people at risk. Lancet 
Infect Dis 6, 411-425.

Stensgaard AS, Utzinger J, Vounatsou P, Hürlimann E, Schur N, Saarnak CF, Simoonga C, Mubita P, Kabatereine NB, Tchuenté LA, Rahbek C, Kristensen TK, 2013. Large-scale determinants of intestinal schistosomiasis and intermediate host snail distribution across Africa: does climate matter? Acta Trop (in press; http://dx.doi.org/10.1016/j.actatropica.2011.11.010)

Stothard JR, Chitsulo L, Kristensen TK, Utzinger J, 2009. Control of schistosomiasis in sub-Saharan Africa: progress made, new opportunities and remaining challenges. Parasitology 136, 1665-1675.

Utzinger J, 2012. A research and development agenda for the control and elimination of human helminthiases. PLoS Negl Trop Dis 6, e1646.

Utzinger J, N'Goran EK, Caffrey CR, Keiser J, 2011. From innovation to application: social-ecological context, diagnostics, drugs and integrated control of schistosomiasis. Acta
Trop 120, S121-S137.

Utzinger J, Raso G, Brooker S, de Savigny D, Tanner M, Ørnbjerg N, Singer BH, N'Goran EK, 2009. Schistosomiasis and neglected tropical diseases: towards integrated and sustainable control and a word of caution. Parasitology 136, 1859-1874.

WHO, 1985. The control of schistosomiasis: report of a WHO expert committee. WHO Tech Rep Ser 728, 1-113.

WHO, 2002. Prevention and control of schistosomiasis and soil-transmitted helminithiasis: report of a WHO expert committee. WHO Tech Rep Ser 912, 1-57.

WHO, 2006. Preventive chemotherapy in human helminthiasis: coordinated use of anthelminthic drugs in control interventions: a manual for health professionals and programme managers. Geneva: World Health Organization.

WHO, 2012. Uniting to combat NTDs. Available at: http://www.unitingtocombatntds.org/ (accessed: 4 February 2012). 